\title{
Assistência do enfermeiro na parada cardiorrespiratória no Serviço de Atendimento
}

\section{Móvel de Urgência (SAMU)}

\author{
Nurse assistance in cardiac arrest in the Mobile Emergency Service (SAMU) \\ Asistencia de enfermería en la parada cardíaca en el servicio de Atención Móvil de Urgencia
}

(SAMU)

\section{Resumo}

Introdução: A parada cardiorrespiratória é responsável por uma elevada taxa de morbimortalidade, mesmo em situações de atendimento ideal. Sua definição consiste na interrupção das atividades respiratória e circulatória efetiva, sua intervenção consiste em aplicar uma série de procedimentos emergenciais, a fim de restabelecer a oxigenação e a circulação. Objetivos: Analisar a assistência do enfermeiro durante uma parada cardiorrespiratória no Serviço de Atendimento Móvel de Urgência. Métodos: Refere-se a uma revisão integrativa da literatura do tipo exploratória com abordagem quantitativa, considerando os materiais disponíveis nas bases de dados BVS e LILACS. Resultados: De acordo com as pesquisas foram geradas duas divisões para apresentação das evidências e discussão da temática. Na primeira, são apresentados: Assistência do profissional enfermeiro no atendimento a vítima em PCR no Serviço de Atendimento Móvel em Urgente. Na segunda divisão apresenta: Fatores determinantes na sobrevida imediata após manobras de ressuscitação cardiopulmonar na Parada cardíaca extra-hospitalar. Conclusão: Foram observados que ainda existe uma escassez de conhecimento sobre o protocolo diante a uma PCR por parte do profissional enfermeiro, voltada para a importância das manobras de RCP com eficiência, visto que o enfermeiro na maioria é o primeiro a chegar no local.

Palavras-chave: Parada cardiorrespiratória; Assistência de enfermagem; SAMU.

\begin{abstract}
Introduction: Cardiac arrest is responsible for a high rate of morbidity and mortality, even in situations of ideal care. Its definition consists of the interruption of effective respiratory and circulatory activities, and its intervention consists of applying a series of emergency procedures in order to reestablish oxygenation and circulation. Objectives: To analyze the nurse's assistance during a cardiac arrest in the Mobile Emergency Care Service. Methods: This is an integrative review of literature of the exploratory type with a quantitative approach, considering the materials available in the BVS and LILACS databases. Results: According to the research, two divisions were generated for presentation of the evidence and discussion of the theme. In the first, they are presented: Assistance of the professional nurse in the care of the victim in CRA in the Mobile Emergency Care Service. The second division presents: Determinant factors of immediate survival after cardiopulmonary resuscitation maneuvers in out-of-hospital cardiac arrest. Conclusion: It was observed that there is still a lack of knowledge about the protocol before a CRA by the professional nurse, focused on the importance of CPR maneuvers with efficiency, since the nurse is mostly the first to arrive at the scene.
\end{abstract}

Keywords: Cardiac arrest; Nursing care; SAMU. 


\section{Resumen}

Introducción: la parada cardíaca es responsable de una alta tasa de morbilidad y mortalidad, incluso en situaciones de atención ideal. Su definición consiste en la interrupción de las actividades respiratorias y circulatorias efectivas, su intervención consiste en la aplicación de una serie de procedimientos de emergencia para restablecer la oxigenación y la circulación. Objetivos: analizar la asistencia del enfermero durante la parada cardiorrespiratoria en el servicio de atención móvil de urgencia. Métodos: se trata de una revisión integradora de la literatura de tipo exploratorio con enfoque cuantitativo, considerando los materiales disponibles en las bases de datos bvs y lilacs. Resultados: de acuerdo con la investigación, se generaron dos divisiones para la presentación de las pruebas y la discusión del tema. En la primera, se presentan: asistencia del profesional enfermero en la atención a la víctima en pcr en el servicio de atención médica urgente. En la segunda división se presenta: factores determinantes de la sobrevida inmediata tras la reanimación cardiopulmonar en la parada cardíaca extrahospitalaria. Conclusión: se ha observado que aún existe un escaso conocimiento sobre el protocolo frente a una pcr por parte del profesional de la enfermería, volcado en la importancia de las maniobras de pcr con eficiencia, dado que el enfermero en su mayoría es el primero en acudir al local.

Palavras-chave: Parada cardiorrespiratoria; Asistencia de enfermería; SAMU.

\section{Introdução}

A parada cardiorrespiratória (PCR) é responsável por uma elevada taxa de morbimortalidade, mesmo em situações de atendimento ideal. Sua definição consiste na interrupção das atividades respiratória e circulatória efetiva, sua intervenção consiste em aplicar uma série de procedimentos emergenciais, a fim de restabelecer a oxigenação e a circulação (Freitas, Fatima, 2009).

O tempo é uma variável importante no atendimento ao paciente; cada minuto de permanência em parada ocorre à diminuição de $10 \%$ da probabilidade de sobrevida do paciente (Freitas \& Fátima, 2009). Algumas das vítimas morrem fora do hospital, pois elas não recebem nenhum atendimento por parte de uma equipe multiprofissional. Embora não tenha um consenso nos dados estatísticos de uma PCR, tem uma média de 200.000 eventos por ano no Brasil, 50\% dos casos ocorrem em ambiente hospitalar e a outra metade em ambientes públicos (González et al., 2013).

O diagnóstico precoce acontece através da verificação da falta do pulso central, movimentos respiratórios ou respiração anormal do tipo "gasping”. As mudanças da parada súbita do sistema circulatório criam dúvidas em relação à hipótese diagnóstica, a expectativa de sobrevida e à recuperação da função cerebral e cardiopulmonar (Silva, 2016).

As causas de PCR dividem-se em primárias e secundárias. É classificado dessa forma para determinar qual conduta deve ser seguida, já que elas variam conforme a causa (Ribeiro júnior et al., 2007).

As causas primárias são as paradas cardíacas que acontece por conta de um problema cardíaco, causando uma arritmia, geralmente a fibrilação ventricular que pode estar associada a isquemia que é a quantidade insuficiente de sangue oxigenado que chega ao coração. As causas secundárias estabelecem as principais causas de PCR em pacientes com traumatismos e crianças. As causas são oxigenação deficiente, devido uma obstrução de vias aéreas e doenças pulmonares; transporte inadequado de oxigênio, ocasionando hemorragias graves, estados de choque e intoxicação pelo monóxido de carbono e ação externas sobre o coração como as drogas, medicamentos e descargas elétricas (Ribeiro júnior et al.,2007).

A ressuscitação cardíaca é um procedimento realizado no intuito de restabelecer uma circulação de sangue oxigenado, principalmente ao coração e ao cérebro, com conservação da permeabilidade tissular, até conseguir a recuperação das funções ventilatórias e cardíacas espontâneas (Silva et al., 2011).

Os objetivos da Ressuscitação Cardiopulmonar (RCP) é de promover a circulação do sangue onde é levado o oxigênio ao cérebro, coração e outros órgãos vitais. Para as condutas serem realizadas de forma correta durante o atendimento de PCR, é indispensável que os profissionais da saúde saibam utilizar os equipamentos necessários, ter conhecimentos diversificado, cogitando melhoria no atendimento (Guilherme et al., [2013]). 
O Enfermeiro possui papel fundamental e importante na assistência ao paciente em parada cardiorrespiratória, a enfermagem auxilia a assistência médica, atuando de maneira correta e ágil, para que o paciente não apresente complicações ou agravos seja no âmbito hospitalar ou no pré-hospitalar (Pereira, Espindola, 2013).

A portaria 2048/ GM de 05 de novembro de 2002, que regulamenta os serviços de urgência e emergência por todo o Brasil, aponta que o Serviço de suporte pré-hospitalar móvel deve ser entendido como uma atribuição da área da saúde, vinculado a uma Central de Regulamentação, com equipe e frota de veículos compatíveis as necessidades de saúde da população, podendo, portanto, ultrapassar os limites municipais. Esta portaria define os tipos de ambulâncias, equipe profissional para cada unidade e as atribuições de cada membro da equipe de apoio (BRASIL, 2006).

Em relação à complexidade do atendimento as unidades do SAMU são divididas em Unidade de Suporte Básico de Vida - USB e Unidade de Suporte Avançado de Vida - USA (BRASIL, 2006).

O SAMU tem o propósito de chegar o mais rápido possível à vítima após ter um acontecimento de urgência ou emergência, e até mesmo à morte. São urgências de natureza clínica, cirúrgica, traumática, obstétrica, pediátrica, psiquiátrica, entre outras. (BRASIL, 2010).

Nessa pespectiva, o estudo da assistência do enfermeiro a vítimas em parada cardiorrespiratória, atendidos pelo serviço de suporte móvel de urgência é bastante válido, tendo-se em vista a indispensabilidade de se aumentar o nível de compreensão sobre a temática e consequente melhoria na assistência pré-hospitalar na tentativa de reverter vítimas em estado de PCR. O enfermeiro como membro da equipe multiprofissional deve estar preparado para fornecer uma abordagem rápida e segura a vítima em PCR, levando em consideração que o sucesso no atendimento depende de conhecimentos e habilidades técnico-científicas e interpessoais.

Portanto, aguarda-se o desenredo dessa pesquisa para o melhoramento da assistência na Ressuscitação Cardiopulmonar, bem como, cooperar com futuros estudos que analisem a assistência da enfermagem durante a PCR. Além disso, deseja-se gerar benefícios científicos, como a melhoria no atendimento dos profissionais de enfermagem, reduzindo a taxa de óbitos devido a PCR e complicações posteriormente a RCP.

A assistência prestada pelo enfermeiro em uma situação de PCR é de suma importância para a sobrevivência do paciente que se encontra em uma situação crítica. Diante do exposto, questionou-se: Qual a assistência do profissional enfermeiro no atendimento a vítima em PCR no Serviço de Atendimento Móvel de Urgência?

\section{Metodologia}

O estudo utilizou como método a revisão integrativa da literatura. Refere-se a uma pesquisa do tipo exploratória com abordagem quantitativa, realizado por meio de levantamento bibliográfico de artigos científicos.

A análise dos dados foi realizada com base na aplicação de cinco etapas: seleção da pergunta de pesquisa; pesquisa bibliográfica; definição dos critérios de inclusão e exclusão dos estudos; seleção da amostra e análise crítica dos achados. Primeiramente foi realizado uma leitura analítica com o intuito de organizar e resumir as informações encontradas nas fontes pesquisadas, sendo usadas para a obtenção da resposta do problema de pesquisa.

As buscas bibliográficas foram realizadas nas seguintes bases de dados internacionais: Literatura Latino-Americana e do Caribe em Ciências da Saúde (LILACS) e na Biblioteca Virtual em Saúde (BVS) no intervalo de 2010 a 2020. Depois de consultar às terminologias em saúde na base de Descritores em Ciência da Saúde (DeCS), os descritores utilizados foram: "Parada cardiorrespiratória", "Assistência de enfermagem" e "SAMU". A busca dos artigos foi realizada juntamente com o operador booleano "AND".

Os dados contidos nos artigos foram levantados pelos pesquisadores em um formulário para categorização dos artigos (Quadro 1) detalhando as características das publicações. 
Os critérios de inclusão foram norteados pela importância do profissional de enfermagem no atendimento a PCR, somente trabalhos publicados na integra que abordassem a temática, publicações em língua portuguesa, e que possuíssem os descritores pré-selecionados pelos autores. No entanto, no critério de exclusão não foi escolhido trabalhos que não deram tal ênfase, textos que se encontravam incompletos, artigos que não estivessem disponíveis na íntegra online, e que não forneciam informações suficientes para a temática.

Figura 1. Fluxograma representativo da seleção dos artigos para estudo. Teresina, 2021.

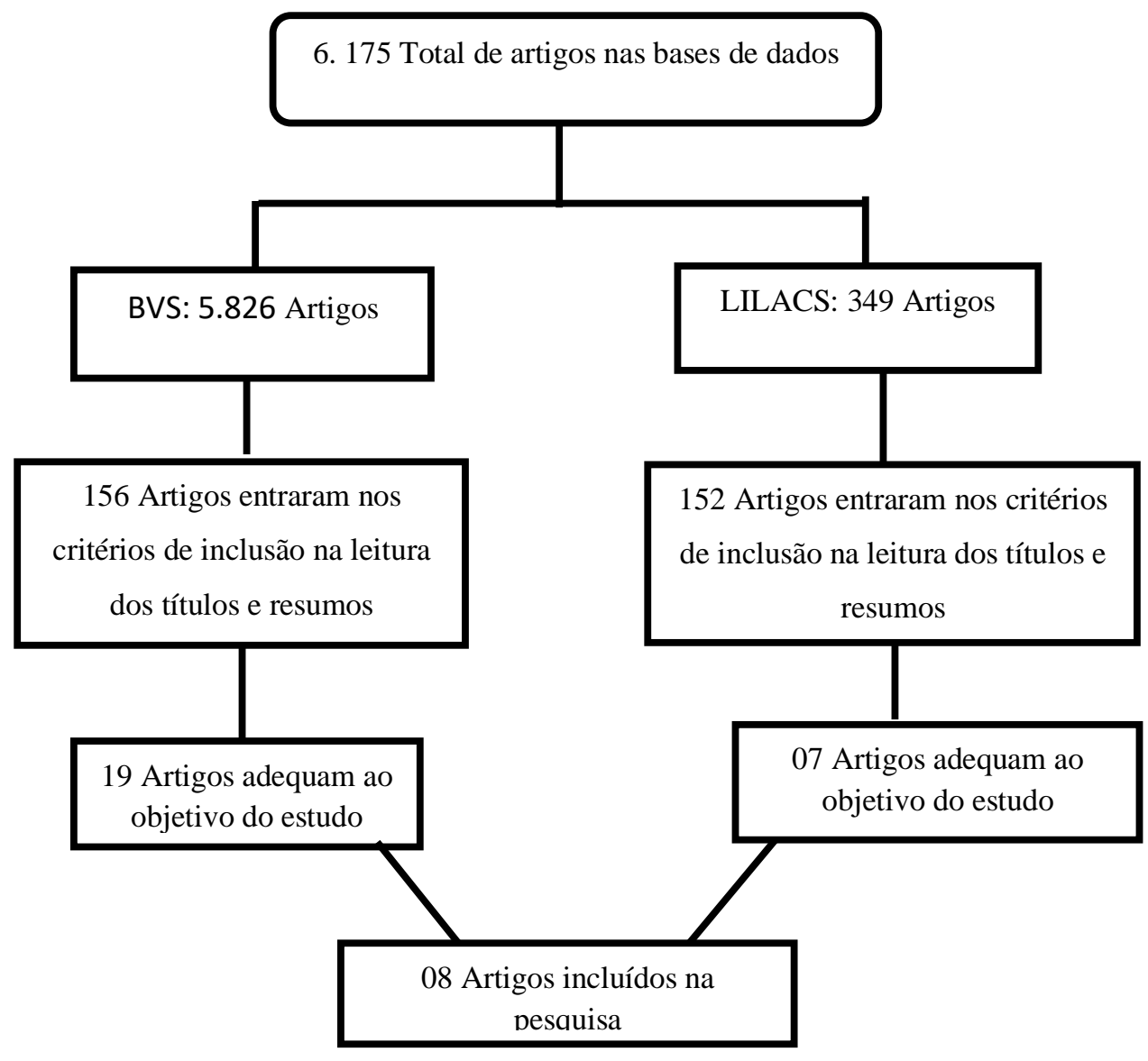

Fonte: Pesquisa direta em base de dados. Teresina-PI, 2021.

Somando-se todas as bases de dados, foram encontrados 6.175 artigos. Após realização dos critérios de inclusão, foram selecionados 308 artigos para leitura de títulos de resumos e excluídos os que não deram tal ênfase no objetivo do artigo. Foram selecionados 26 artigos para leitura na íntegra, após leitura foram selecionados 08 artigos para análise e categorização, conforme a figura 1 apresenta.

Foi realizado a análise de maneira criteriosa dos artigos de forma a serem revisados pelos dois pesquisadores sendo subjugados em concordância com os critérios de inclusão e exclusão metodológica de forma a ser elaborada a apresentação dos dados obtidos.

\section{Resultados}

O Quadro 1 exibe os estudos que compuseram esta revisão integrativa, no que se refere ao título, ano, autores e objetivos. 
Quadro 1: Características dos estudos conforme o título, ano, autores, objetivos. Teresina, 2021.

\begin{tabular}{|c|c|c|c|c|}
\hline $\mathrm{N}^{\mathrm{o}}$ & TÍTULO & ANO & AUTORES & OBJETIVO \\
\hline 01 & $\begin{array}{l}\text { Parada cardiorrespiratória: intervençoes } \\
\text { dos profissionais de enfermagem }\end{array}$ & 2020 & $\begin{array}{l}\text { Santiago BMG, Oliveira JS, } \\
\text { Morais RLGL, Santos ISC, } \\
\text { Cunha DO }\end{array}$ & $\begin{array}{l}\text { Objetivou avaliar se os conhecimentos dos } \\
\text { profissionais frente a parada cardiorrespiratória } \\
\text { (PCR) estão de acordo com o protocolo da } \\
\text { American Heart Association-AHA. }\end{array}$ \\
\hline 02 & $\begin{array}{l}\text { Parada Cardiorrespiratória: } \\
\text { caracterização do atendimento no } \\
\text { serviço de atendimento móvel de } \\
\text { urgência }\end{array}$ & 2020 & $\begin{array}{l}\text { Brandão PC, Silva ICN, } \\
\text { Farias MTD, Santos VPFA, } \\
\text { Farias DMF, Cruz VSS, } \\
\text { Oliveira JA }\end{array}$ & $\begin{array}{l}\text { Descrever as caractéristicas do atendimento às } \\
\text { vítimas de parada cardiorrespiratória no ambiente } \\
\text { pré-hospitalar }\end{array}$ \\
\hline 03 & $\begin{array}{l}\text { Conhecimento da equipe de } \\
\text { enfermagem sobre ressuscitação } \\
\text { cardiopulmonar }\end{array}$ & 2019 & 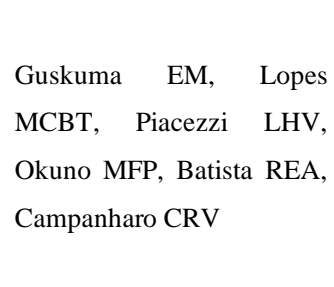 & $\begin{array}{l}\text { Objetivou-se idenificar o conhecimento teórico } \\
\text { da equipe de enfermagem sobre as manobras de } \\
\text { ressuscitação cardiopulmonar em suporte básico } \\
\text { de vida, associado tal conhecimento às variáveis } \\
\text { sociodemográficas, econômicas e de formação } \\
\text { profissional. }\end{array}$ \\
\hline 04 & $\begin{array}{l}\text { Atendimento a pacientes em } \\
\text { situaçãoes de urgência: do serviço pré- } \\
\text { hospitalar móvel ao serviço hospitalar } \\
\text { de emergência }\end{array}$ & 2019 & $\begin{array}{l}\text { Cunha VP, Erdmann AL, } \\
\text { Santos JLG, Menegon } \\
\text { FHA, Nascimento KC. }\end{array}$ & $\begin{array}{l}\text { O objeivo dessa pesquisa foi compreender o } \\
\text { atendimento ao paciente em situação de urgência } \\
\text { desde o serviço pré-hospitalar móvel dao serviço } \\
\text { hospitalar de emergência. }\end{array}$ \\
\hline 05 & $\begin{array}{l}\text { O conhecimento do profissional de } \\
\text { enfermagem frente à parada } \\
\text { cardiorrespiratória segundo as novas } \\
\text { diretrizes e atualizações }\end{array}$ & 2018 & $\begin{array}{l}\text { Barbosa JSL, Moraes-Filho } \\
\text { IM, Pereira BA, Soares SR, } \\
\text { Silva W, Santos OP. }\end{array}$ & $\begin{array}{l}\text { O objetivo deste trabalho é identificar se os } \\
\text { profissionais enfermeiros têm conhecimento } \\
\text { técnico científico sobre as novas diretrizes e } \\
\text { Ressuscitação Cardiopulmonar (RCP). }\end{array}$ \\
\hline 06 & $\begin{array}{l}\text { Diretrizes da American Heart } \\
\text { Association para ressusitação } \\
\text { cardiopulmonar: } \\
\text { socorristas }\end{array}$ & 2017 & $\begin{array}{l}\text { Salazar ERS, Gaspar ESL, } \\
\text { Santos MS }\end{array}$ & $\begin{array}{l}\text { Descrever o conhecimento dos profissionais } \\
\text { socorristas sobre o protocolo da American Heart } \\
\text { Association para ressucitação cardiopulmonar. }\end{array}$ \\
\hline 07 & $\begin{array}{l}\text { Parada cardíaca extra-hospitalar: fatores } \\
\text { determinantes da sobrevida imediata } \\
\text { após manobras de ressusciação } \\
\text { cardiopulmonar }\end{array}$ & 2014 & $\begin{array}{l}\text { Morais DA, Carvalho DV, } \\
\text { Correa AR }\end{array}$ & $\begin{array}{l}\text { Analisar fatores determinantes da sobrevida } \\
\text { imediata de pessoas que receberam manobras de } \\
\text { ressuscitação cardiopulmonar pelas equipes de } \\
\text { suporte avançado do Serviço de Atendimento } \\
\text { Móvel de Urgência, de Belo Horizonte }\end{array}$ \\
\hline 08 & $\begin{array}{l}\text { Suporte básico à vida em adultos: } \\
\text { conhecimentos dos enfermeiros sobre as } \\
\text { diretrizes } 2010-2015\end{array}$ & 2013 & $\begin{array}{l}\text { Silva JN, Montezeli JH, } \\
\text { Gastaldi AB }\end{array}$ & $\begin{array}{l}\text { Identificar o conhecimento dos enfermeiros } \\
\text { sobre as diretrizes de ressuscitação } \\
\text { cardiopulmonar 2010-2015 para suporte básico à } \\
\text { vida em adultos. }\end{array}$ \\
\hline
\end{tabular}

Fonte: Pesquisa direta em base de dados, Teresina, 2021.

No quadro 2 foram organizados os estudos segundo o assunto principal destacado em seus contéudos após leitura completa. 
Quadro 2: Organização dos estudos com o foco das evidencias apresentadas. Teresina, 2021.

\begin{tabular}{|l|l|}
\hline ARTIGOS & EVIDÊNCIAS \\
\hline $1,3,5,6,7$ & $\begin{array}{l}\text { Assistência do profissional enfermeiro no atendimento a vítima em } \\
\text { PCR no Serviço de Atendimento Móvel em Urgente }\end{array}$ \\
\hline $2,4,7,8$ & $\begin{array}{l}\text { Fatores determinantes na sobrevida imediata após manobras de } \\
\text { ressuscitação cardiopulmonar na Parada cardíaca extra-hospitalar. }\end{array}$ \\
\hline
\end{tabular}

Fonte: Pesquisa direta em base de dados. Teresina, 2021.

Conforme a estruturação dos estudos observados acima, foram geradas duas divisões para apresentação das evidências e discussão da temática. Na primeira divisão são apresentados: Assistência do profissional enfermeiro no atendimento ao paciente em PCR no Serviço de Atendimento Móvel em Urgente. Já a segunda divisão apresenta: Fatores determinantes na sobrevida rápida após manobras de ressuscitação cardiopulmonar na Parada cardíaca extra-hospitalar.

\section{Discussão}

\subsection{Assistência do profissional enfermeiro no atendimento a vítima em PCR no Serviço de Atendimento Móvel em} Urgente

Segundo Morais, Carvalho e Correa (2014) a parada cardiorrespiratória é a emergência clinica mais critica e com péssima estimativa, podendo ser um momento breve, reversível com probabilidade de vítimas se restabelecerem e retornarem as suas atividades. Pórtanto, é significativo que ensinamentos sobre a sobrevida tardia e sobrevida em amplo prazo sejam realizados.

Segundo a American Heart Association (AHA) 2015, a PCR representa uma mudança súbita e incomum no bombeamento de sangue, que produz ritmo inadequado ou ausência dele, onde a vida não pode ser mantida. Quando há parada cardiorrespiratória, poderão acontecer danos celulares irreversíveis e lesões cerebrais graves e irreversíveis, principalmente após os primeiros cincos minuto de parada.

Guskuma et al. (2020) relatam que os profissionais com especialização em áreas não críticas apresentam menor número de acertos nos atendimentos sobre PCR.

Houveram avanços significativos nos anos anteriores relacionados à prevenção e ao tratamento da PCR e alterações cardiovasculares, mas ainda há um número alto de mortes associadas a este acontecimento. A assistência a vítima de PCR decorre do rápido reconhecimento e da execução das manobras de RCP e rápida desfibrilação; para isto, torna-se fundamental que a equipe de saúde tenha preparo e conhecimento nestas manobras. Esses aspectos são fundamentais e podem fazer a diferença na sobrevida e na diminuição de sequelas (Bukiran, Erdur, Ozen, Bozkurt, 2014).

Nos estudos de Moraes, Paula, Silva \& Rodriguez (2016) o enfermeiro tem o dever prioritário de prestar assistência aos pacientes graves, na PCR não é diferente. Porém, sua função frente a uma RCP é bem mais ampla, além de realizar manobras de reanimação, providenciar recursos materiais, deve dar suporte a equipe e treinamento continuado, para que as condições de atendimento sejam realizadas de forma adequada e com qualidade.

Para Salazar, Gaspar \& Santos (2017), em pesquisa realizada, mais de 57,3\% dos profissionais entrevistados responderam conhecer as novas diretrizes da AHA para reanimação cardiopulmonar e 42,5\% disseram que não. Quando questionados sobre o assunto apenas $62,3 \%$ dos participantes que afirmaram conhecer o protocolo acertaram a sequência correta das manobras de reanimação cardíaca. Destacando-se que, nesse quesito, o percentual dos participantes que afirmaram desconhecimento do protocolo atual foi relativamente maior, o que gera prejuízos na assistência prestada. 
O estudo de Santiago, Oliveira, Santos, Morais, Santos \& Cunha (2020) demonstra que o conhecimento do profissional enfermeiro em associação ao reconhecimento da PCR é limitado, ocorreu que $81 \%$ dos profissionais de enfermagem responderam de forma correta saber como agir após o reconhecimento de uma PCR. Apesar do protocolo da AHA se atualizado a cada cinco anos, nota-se que alguns profissionais vão acompanhando os novos protocolos.

Uma outra etapa importante é a administração rápida e segura de medicamentos durante a RCP para aumentar a eficácia das manobras que estão sendo realizadas. Segundo Barbosa et al. (2018) as medicações relatadas como sendo as mais usadas durante a parada cardiorrespiratória pelos profissionais enfermeiros foi adrenalina descrita por 94,44\%; segundo de $66,66 \%$ dos profissionais descreveram amiodarona e cerca de 44,4\% descreveram atropina. É papel da equipe a prática de RCP contínua, a monitoração do ritmo cardíaco e dos outros sinais vitais, a administração de fármacos, registros de acontecimentos, manuseio do carro de emergência e manuseio de equipamentos específicos, como o kit de intubação orotraqueal.

\subsection{Fatores determinantes na sobrevida imediata após manobras de ressuscitação cardiopulmonar na Parada cardíaca extra-hospitalar.}

Nos estudos de Silva et al. (2013) a RCP é uma atividade sistemática e complexa que envolve diversos fatores e o profissional de enfermagem está inserido nesse conjunto. Ele pode auxiliar de forma participativa e compartilhada, ou mesmo delegando atribuições para um melhor prognóstico do paciente. Destarte, para o enfermeiro realizar seu papel de líder da sua equipe, deve estar atualizado em relação às alterações no protocolo de RCP.

Segundo Morais, Carvalho e Correa (2014), a resposta da ambulância, ocorre em instantes, entre a transmissão do chamado à equipe pela Central de Regulação até mesmo a chegada da ambulância ao local determinado é um dos critérios de comportamento de um serviço de atendimento pré-hospitalar.

A comunicação é fundamental desde o recebimento da chamada até o seu desdobramento na função hospitalar de emergência autorizando que os profissionais ajam de maneira complementar e proporcionando a integralidade da assistência. (Siqueira, Rennó, Ferreira, Ferreira, Paiva, 2017)

Cunha, Erdmann, Santos, Menegon \& Nascimento (2019), o atendimento é realizado em um ambiente aberto e não controlado, os profissionais buscam prover um atendimento de qualidade em tempo prático dentro das condições ambientes e disponíveis. As equipes do suporte pré-hospitalar interagem entre si durante as ocorrências e buscam, quando necessário, ajuda um do outro para a assistência do paciente.

O motivo mais preocupante para vítima com PCR é o intervalo transcorrido entre o início do colapso até o início da intervenção e da possibilidade de sobrevida é menor se esse evento não é visto por alguém. (Morais, Carvalho, Correa, 2014). É de extremo valor a qualificação dos cidadãos para desempenharem frente à PCR, visto que a execução de manobras de RCP, até o acesso do serviço médico de emergência, elevando a chance de sobrevida do paciente. (SASSON, Rogers, Dahl, Kellermann, 2010).

A PCR é provida por quatro ritmos cardíacos: assistolia, atividade elétrica sem pulso, fibrilação ventricular (FV) e taquicardia ventricular sem pulso, sendo os dois últimos ritmos tratados com choque elétrico no coração por um desfibrilador. (Patil, Halperin, Becker, 2015).

Segundo a AHA (2010) o sucesso da sobrevida do paciente após uma PCR está na qualidade da RCP. Para tanto, os profissionais de saúde deverão seguir alguns critérios que serão realizados frente a essa emergência clínica: reconhecimento imediato da PCR, que visa o início das manobras e a comunicação da ocorrência objetivando ajuda; RCP precoce, na qual ocorrerá a abertura de vias aéreas, ventilação e circulação sanguínea com ênfase nas compressões torácicas, que devem ocorrer tão breve possível; rápida desfibrilação, com identificação e tratamento da Fibrilação Ventricular (FV), está se configura em 
um passo de extrema relevância, pois é quando se tentará reestabelecer o ritmo cardíaco; e por fim, a aplicação das técnicas do Suporte Avançado de Vida (SAV) que visam o controle das vias aéreas e medicamentos apropriados ao ritmo cardíaco, bem como os cuidados pós-PCR.

No estudo de Cunha, Erdmann, Santos, Menegon \& Nascimento (2019) as ações realizadas para o suporte à vítima são realizadas de forma sistemática, organizada e ordenada e tem como dar continuidade a um atendimento iniciado. Nas bases operacionais, os grupos atuantes no serviço de assistência pré-hospitalar móvel aguardam pelo acionamento. Quando acionadas, as equipes deslocam-se para o local apontado pela central. Ao chegar, relatam a ocorrência para a central e dão início a assistência ao paciente. No decorrer do atendimento ao paciente, os profissionais reportam-se frequentemente a central de regulamentação informando sobre a gravidade do quadro clínico do paciente, solicitando apoio e procurando informações sobre o hospital para qual o paciente deve ser direcionado. Durante a ocorrência, a central de regulamentação tem papel fundamental na articulação entre os diferentes profissionais envolvidos no caso.

Segundo Morais, Carvalho \& Correa (2014) destacou no seu estudo que os pacientes acometidos por parada cardiorrespiratória de que modo aos antecedentes mórbidos, avaliou-se que, das fichas que havia o registro dessa informação, a hipertensão arterial sistêmica, as doenças cardíacas e o diabetes mellitus foram os mais dominantes. No entanto, a maior parte dos pacientes que receberam manobras de RCP não possuía nenhuma comorbidade relatada.

Em contrapartida, Brandão et al. (2019) relata que os estudos confirmam que, apesar de consideráveis esforços e avanços atingidos na última década, no campo de prevenção, tratamento e através de estratégias que aumentam as possibilidades de êxito na RCP, a sobrevivência da PCR extra-hospitalar continua sendo baixa.

\section{Conclusão}

Com a pesquisa constatou-se que a parada cardiorrespiratória (PCR) tem uma elevada taxa de morbimortalidade, onde consiste na interrupção da atividade respiratória e circulatória efetiva, sua intervenção consiste em aplicar uma série de procedimentos emergenciais, a fim de reestabelecer a oxigenação e a circulação, sobretudo o diagnóstico precoce é através da verificação de falta de pulso central, movimentos respiratórios ou respiração anormal do tipo "gasping", compreendendo os sinais da PCR.

Notou-se no estudo, que muitos profissionais possuem uma deficiência no conhecimento sobre as novas diretrizes da AHA, o que reflete no atendimento aos pacientes. O objetivo da RCP é promover a circulação do sangue onde é levado o oxigênio ao cérebro, coração e outros órgãos vitais, para as condutas serem realizadas de forma correta durante o atendimento de

PCR, é indispensável que os profissionais de saúde tenham conhecimento técnico-científico, noção no manuseio dos equipamentos necessários e drogas mais utilizadas, ter conhecimentos diversificado cogitando melhoria no atendimento.

Foram observados que ainda existe uma necessidade de implementação de conhecimento sobre o protocolo diante a uma PCR por parte do profissional enfermeiro, voltada para a importância das manobras de RCP com eficiência, visto que o enfermeiro na maioria é o primeiro a chegar no local. Desta forma, visa a carência de capacitar os profissionais no atendimento ao paciente em parada cardiorrespiratória como melhoria no atendimento dos profissionais de enfermagem, reduzindo a taxa de óbitos devido a PCR e complicações posteriormente a RCP.

Nesse sentido, sugere-se mais estudos abordando a temática em busca por mais conhecimentos cuja finalidade seja preparar o profissional de enfermagem para atuar frente a PCR com uma abordagem eficiente e proativa.

\section{Referências}

AHA. (2015). American Heart Association. Destaques da American Heart Association 2015. Atualização das Diretrizes de RCP e ACE. 
Research, Society and Development, v. 10, n. 6, e6510615651, 2021

(CC BY 4.0) | ISSN 2525-3409 | DOI: http://dx.doi.org/10.33448/rsd-v10i6.15651

AHA. (2010). American Heart Association. Destaques das Diretrizes da American Heart Association 2010 para RCP e ACE.

Barbosa, J. S. L., Moraes-filho I. M., Pereira B. A., Soares S. R., Silva W. \& Santos O. P. O conhecimento do profissional de enfermagem frente à parada cardiorrespiratória segundo as novas diretrizes e suas atualizações. Rev. Cient. Sena Aires. 2018;7(2): 117-26.

Brandão, P. C., Silva, I. C. N., Santos, V. P. F. A., Farias, D. M. F., Cruz, V. S. S. \& Oliveira, J. A. (2020). Parada Cardiorrespiratória: caracterização do atendimento no serviço de atendimento móvel de urgência. Revista Nursing. 23(267):4466-4471.

Brasil. (2010). Ministério da Saúde. Roteiro para elaboração do projeto - SAMU 192.

Brasil. (2006). Política nacional de atenção as urgências: Ministério da Saúde. Brasília. Editora do Ministério da Saúde.

Bukiran, A., Erdur, B., Ozen, M. \& Bozkurt, A. I. (2014). Retention of nurses` knowledge after basic life support and advanced cardiac life support training at immediate, 6-month, and 12-month post-training interval: a longitudinal study of nurses in Turkey. J Emerg Nurs. Março. 40 (2): $146-52$.

Cunha, V. P., Erdmann, A. L., Santos, J. L. G., Menegon, F. H. A. \& Nascimento, K. C. (2019). Atendimento a pacientes em situação de urgência: do serviço pré-hospitalar móvel ao serviço hospitalar de emergência. Rev. Enfermaría Actual. n.37, julho.

Freitas, L. M. \& Fatima, L. A. (2009). Parada cardiorrespiratória do paciente adulto no âmbito intra-hospitalar: subsídios para a enfermagem. Rev. Gaúcha Enferm. Porto Alegre (RS) v.30, n.2, p.328-337, jun.

Gonzales, M. M., et al. (2013). I Diretrizes de ressuscitação cardiopulmonar e cuidados cardiovasculares de emergência da sociedade brasileira de cardiologia. Arq. Bras. Cardiologia, v. 101, n. 2, Agosto.

Guilherme, M. I. S., et al. (2013). O atendimento de enfermagem em casos de parada cardiorrespiratória (PCR).

Guskuma, E. M., Lopes, M. C. B. T., Piacezzi, L. H. V., Okuno, M. F. P., Batista, R. E. A. \& Campanharo, C. R. V. (2019). Conhecimento da equipe de enfermagem sobre ressuscitação cardiopulmonar. Rev. Eletr. Enferm. 21:52253, 1-8.

Moraes, C. L. K., Paula, G. M. A., Silva, J. R. \& Rodrigues, M. C. L. (2016). Desafios enfrentados pela equipe de enfermagem na reanimação cardiorrespiratória em uma unidade de emergência hospitalar. Rev. Eletr. Estácio Saúde. v.5. n.1.

Morais, D. A., Carvalho, D. V. \& Correa, A. R. (2014). Parada cardíaca extra-hospitalar: fatores determinantes da sobrevida imediata após manobras de ressuscitação cardiopulmonar. Rev. Latino-Am. Enfermagem.jul.-ago.22(4):562-8.

Patil, K. D., Halperin, H. R. \& Becker, L. B. (2015). Cardiac arrest: resuscitation and reperfusion. Circ Res.116(12):2041-9.

Pereira, N. L. \& Espindula, B. M. (2013). Conduta de enfermagem frente ao paciente em parada cardiorrespiratória-PCR. Revista Eletrônica de Enfermagem do Centro de Estudos de Enfermagem e Nutrição, ago-dez 4(4),1-15.

Ribeiro Junior, C., et al. (2007). Manual Básico de Socorro de emergência. 2 ed. São Paulo: Atheneu.

Salazar, E. R. S., Gaspar, E. S. L. \& Santos, M. S. (2017). Diretrizes da American Heart Association para ressuscitação cardiopulmonar: conhecimentos de socorristas. Rev. Baiana enferm. 31(3):e20449.

Santiago, B. M. G., Oliveira, J. S., Santos, C. S., Morais, R. L. G. L., Santos, I. S. C. \& Cunha, D. O. (2020). Parada cardiorrespiratória: intervenções dos profissionais de enfermagem. Revista online de pesquisa. jan/dez; 12:1105-1109.

Sasson, C., Rogers, M. A., Dahl, J. \& Kellermann, A. L. (2010). Predictors of survival from out-of-hospital cardiac arrest - a systematic review and metaanalysis. Circ Cardiovasc Qual Outcomes. 3(1):63-81.

Silva, A. C. (2016). Desenvolvimento de ambiente virtual de aprendizagem para a capacitação em parada cardiorrespiratória. Tese de doutorado. Universidade de São Paulo.

Silva, F. V., et al. (2011). Importância do treinamento em reanimação cardiopulmonar para profissionais de saúde.EFDeportes.com. Revista Digital. Buenos Aires, ano16, n.156.

Silva, J. N., Montezeli, J. H. \& Gastaldi, A. B. (2013). Suporte básico à vida em adultos: conhecimentos do enfermeiros sobre as diretrizes 2010-2015. Rev. Enferm. UFPE on line. Recife, 7(5): 1256-63 maio.

Siqueira, C. L., Rennó, D. S., Ferreira, N. M. C., Ferreira, S. L. \& Paiva, S. M. A. (2017) Difficulties perceived by nursing in the daily work of a mobile service of urgency. Revista saúde. 11(1-2): 62-73. 